ББК 63.4

\author{
Организация конференциии и издание материалов проведень \\ при финансовой поддержке Российского фонда фундаментальных исследований, \\ проект № 19-09-20008
}

Утверждено к печати Ученым советом ИИМК РАН

Редакционная коллегия тома I: В. А. Алёкшин, Л. Б. Кирчо (отв. редакторы),

В. П. Никоноров, В. Я. Стёганцева; В. В. Терёхина

Рецензенты: д. и. н. Л. Б. Вишняцкий, д. и. н. А. А. Выборнов

Программный комитет конференции: академик РАН, д. и. н., проф. М. Б. Пиотровский

(Государственный Эрмитаж, почетный председатель); д. и. н. В. А. Лапшин (ИИМК РАН, председатель); д. и. н. А. В. Головнёв (МАЭ РАН, сопредседатель); д. и. н. В. А. Дергачёв (Высшая антропологическая школа, Молдова, сопредседатель); д. и. н. И. Ф. Попова (ИВР РАН, сопредседатель); академик АН Республики Узбекистан, д. и. н., проф. Э. В. Ртвеладзе (сопредседатель); к. и. н. А. В. Поляков (ИИМК РАН, зам. председателя); к. и. н. В. А. Алёкшин (ИИМК РАН, зам. председателя); д. и. н. Ю. Е. Берёзкин (МАЭ РАН); Dr., Prof. Н. Бороффка (Германский археологический институт, Германия); В. С. Бочкарёв (ИИМК РАН); Dr. Э. Кайзер (Свободный университет Берлина, Германия); к. и. н. М. Т. Кашуба (ИИМК РАН); д. и. н. Л. Б. Кирчо (ИИМК РАН); к. и. н. А. В. Кияшко (Южный федеральный университет); к. и. н. П. Ф. Кузнецов (СГСПУ);

к. и. н. Н. М. Малов (СНИГУ); к. и. н. В. П. Никоноров (ИИМК РАН); Ю. Ю. Пиотровский

(Государственный Эрмитаж); д. и. н., проф. Д. Г. Савинов (Институт истории СПбГУ);

к. и. н. В. Н. Седых (Институт истории СПбГУ); к. и. н. Н. Н. Скакун (ИИМК РАН);

к. и. н. Н. Ф. Соловьёва (ИИМК РАН); к. и. н. А. И. Торгоев (Государственный Эрмитаж); к. и. н. Е. А. Черлёнок (Институт истории СПбГУ)

Организационный комитет конференции: к. и. н. А. В. Поляков (ИИМК РАН, председатель);

к. и. н. В. А. Алёкшин (ИИМК РАН, зам. председателя); В. С. Бочкарёв (ИИМК РАН); ); к. и. н. М. Т. Кашуба (ИИМК РАН); д. и. н. Л. Б. Кирчо (ИИМК РАН);

А. И. Климушина (ИИМК РАН, отв. секретарь); к. и. н. В. П. Никоноров (ИИМК РАН); Ю. Ю. Пиотровский (Государственный Эрмитаж); В. Я. Стёганцева (ИИМК РАН); В. В. Терёхина

(ИИМК РАН, МАЭ РАН, отв. секретарь); к. и. н. Е. С. Ткач (ИИМК РАН); И. Ж. Тутаева (Государственный Эрмитаж); к. и. н. Е. А. Черлёнок (Институт истории СПбГУ)

Древности Восточной Европы, Центральной Азии и Южной Сибири в контексте связей и взаимодействий в евразийском культурном пространстве (новые данные и концепции): Материалы Международной конференции, 18-22 ноября 2019 г., Санкт-Петербург. Т. I. Древняя Центральная Азия в контексте евразийского культурного пространства (новые данные и концепции). К 90-летию со дня рождения патриарха евразийской археологии Вадима Михайловича Массона. - СПб.: ИИМК РАН, Невская Типография, 2019. — 291 с.

ISBN 978-5-907053-34-2

DOI 10.31600/978-5-907053-34-2 
Технологически и по составу красителей ворсовые изделия неоднородны, а их находки имеются как в ранних, так и поздник курганах пазырыкской культуры, датируемых с конца VI - начала V в. до н. э. (Башадар, кург. 2) до середины III в. до н. э. (Пазырык, кург. 5). Можно предположить, что на протяжении всего времени существования пазырыкской культуры имелись постоянные источники поступления ворсовых тканей, а часть их, возможно, была изготовлена самими носителями пазырыкской культуры.

\title{
Литература
}

Полосьмак Н. В., Баркова Л. Л. 2005. Костюм и текстиль пазырыкцев Алтая (IV-III вв. до н. э.). Новосибирск.

Полосьмак Н. В., Кундо Л. П., Балакина Г. Г., Маматюк В. И., Васильев В. Г., Карпова Е. В., Малахов В. В., Власов А. А., Краевская И. Л., Довлитова Л. С., Королюк Е. А., Царева Е. Г. 2006. Текстиль из «замерзших» могил Горного Алтая IV-III вв. до н. э. (опыт междисциплинарного исследования). Новосибирск.

Руденко С. И. 1968. Древнейшие в мире художественные ковры и ткани из оледенелых курганов Алтая. М.

\section{PILE TEXTILES FROM THE PAZYRYK BARROWS: TECHNOLOGY FEATURES AND A PROBLEM OF THE ORIGIN}

Svetlana V. Pankova, Elena V. Stepanova, Ludmila S. Gavrilenko

The State Hermitage Museum, St. Petersburg, Russia

Keywords: Pazyryk culture, Scythian times, textiles, pile fabrics, technology, dyes

The paper presents systematized data on the one-coloured pile products from the monuments of the Pazyryk culture. Considered are the scope of the application of such textiles, options for the technology used, and data on the composition of the dyes. A review of close-in-time finds of pile products from the territories of Central Asia and the Near East is given.

\section{МАССАГЕТЫ ГЕРОДОТА И САКИ ТИГРАХАУДА АХЕМЕНИДСКИХ НАДПИСЕЙ: СООТНОШЕНИЕ И ЛОКАЛИЗАЦИЯ}

\author{
А. С. Балахванцев \\ Институт востоковедения РАН, Москва, Россия
}

DOI: $10.31600 / 978-5-907053-34-2-260-262$

Ключевые слова: массагеты, саки тиграхауда, ортокорибантии.

В науке существуют самые разнообразные мнения относительно локализации упоминаемых в царских надписях Ахеменидов саков тиграхауда: Памир, Тянь-Шань, Семиречье, Ташкентский оазис, правобережье Сырдарьи, западные районы Восточного Туркестана, запад или северо-восток Средней Азии (Литвинский 1972: 159-161). Столь же разнятся взгляды исследователей на то, являются ли саки тиграхауда и массагеты античной нарративной традиции одним народом или не имеют между собой ничего общего.

Анализ сохранившихся у греческих и латинских авторов сведений о массагетах VIIV вв. до н. э. показывает, что наиболее обоснованной является их локализация к северу от Узбоя, между Каспийским морем и Южным Приаральем. Вместе с тем присутствие в Мидии племени ортокорибантиев, имя которых являлось калькой с древнеперсидского tigraxaudā и означало «острошапочные», свидетельствует, что они не могли быть никем 
иным, как частью переселившихся в Мидию саков тиграхауда. Логично предположить, что наиболее вероятной отправной точкой подобного переселения были территории, расположенные в западной части Средней Азии, к востоку от Каспия. Данные обстоятельства позволяют отождествить массагетов Геродота c sakā tigraxaudā ахеменидских надписей (Балахванцев 2014: 90), что уже не раз предлагалось в литературе (Литвинский 1972: 172; Ягодин 2011: 162).

В археологическом плане массагеты/саки тиграхауда соответствовали ранним сакам Присарыкамышской дельты Амударьи. Однако, вопреки встречающимся утверждениям (Ягодин 2011: 162), они уже в VIII-VII вв. до н. э. освоили также Арало-Каспийское междуморье. В пользу ранней даты обживания этой территории свидетельствует находка, являющихся характерным признаком раннескифской культуры (Медведская 1992: 87), стремечковидных бронзовых удил возле святилища Кайнар 1 на Устюрте (Самашев и др. 2011: 24, рис. 21).

В докладе также отмечается, что проявляющаяся в последние годы тенденция поставить это тождество под сомнение основана либо на весьма спорном подходе к такому виду эпиграфических источников как царские надписи, исключающем критическое отношение к последним (Немировский 2005: 221-223; Иванов 2015: 117), либо на не имеющих ничего общего с наукой попытках представить массагетов тюрками (Исмагил 2007: 109-110).

\section{Литература}

Балахванцев А. С. 2014. К вопросу о происхождении топонима Партава // Восток. Афроазиатские общества: история и современность. 2. С. 87-91.

Иванов С. С. 2015. К вопросу об этнической идентификации древних кочевников Притяньшанья в сакский период // Зенько-Немчинова М. А., Иванов С. С. (ред.). Комплексный подход в изучении природы, общества и человека: ММНК, посвящ. 110-летию со дня рождения выдающегося ученого-этнолога С. М. Абрамзона. Бишкек. С. 116-121.

Исмагил Р. 2007. «Саки тиграхауда» и проблема этнической атрибуции племен степной Евразии эпохи раннего железа // Бисембаев А. А. (ред.). ММНК «Кадырбаевские чтения-2007». Актобе. С. 108-112.

Литвинский Б. А. 1972. Древние кочевники «Крыши Мира». М.

Медведская И.Н. 1992. Периодизация скифской архаики и Древний Восток // РА. № 3. С. 86-107.

Немировский А. А. 2005. Массагеты Геродота и саки тиграхауда // Дандамаева М. М. (ред.). Эдубба вечна и постоянна: Материалы конф., посвящ. 90-летию И. М. Дьяконова. СПб. C. 217-223.

Самашев 3., Онгар А., Оралбай Е., Киязбек Г. 2011. Храм-святилище Кызылуийк. Астана. Ягодин В. Н. 2011. Саки-тиграхауда - массагеты Арало-Каспия // Ажигали С. Е. (ред.). Арало-Каспийский регион в истории и культуре Евразии. Алматы; Актобе. С. 160-163.

\section{HERODOTUS' MASSAGETAE AND THE SAKĀ TIGRAXAUDĀ OF THE ACHAEMENID INSCRIPTIONS: CORRELATION AND LOCALIZATION}

Archil S. Balakhvantsev

Institute of Oriental Studies, Moscow, Russia

Keywords: Herodotus, Massagetae, Old Persian inscriptions, Sakā tigraxaudā, Orthocorybantians.

Analysis of the information concerning the Massagetae of the $6^{\text {th }}-4^{\text {th }}$ centuries $\mathrm{BC}$, which is preserved by Greek and Latin authors, shows that the most justified is their localization north of the 
Uzboy river, between the Caspian Sea and the Southern Aral Sea area. At the same time, the presence in Media of a tribe of the Orthocorybantians, whose name was a calque of the Old Persian tigraxauda and meant "with pointed caps", indicates that they could not be anyone else but part of the Sakā tigraxaudā who migrated to Media. It is logical to assume that the most plausible starting point for such a migration were the territories located in the western part of Central Asia, between the Caspian and the Aral seas. These circumstances make it possible to identify the Massagetae of Herodotus with the Sakā tigraxaudā of the Achaemenid inscriptions. It should be also noted that the tendency appearing in the recent years to put this identity in doubt is based on a very controversial approach to such a kind of epigraphic sources as the royal inscriptions, which excludes any critical attitude towards them.

\title{
НОВЫЙ ПАМЯТНИК РАННИХ КОЧЕВНИКОВ НА ЮГЕ ТАДЖИКИСТАНА: МОГИЛЬНИК ШАХИДОН (К ПРОБЛЕМЕ ВЗАИМОДЕЙСТВИЯ ПОДВИЖНЫХ СКОТОВОДОВ И ЗЕМЛЕДЕЛЬЦЕВ)
}

\author{
Т. Г. Филимонова ${ }^{\star}$, Н. Сайфуллоев ${ }^{\star}$, Н. А. Дубова ${ }^{\star \star}$, Р. М. Сатаев ${ }^{\star \star}$, В. В. Куфтерин ${ }^{\star \star}$, \\ Л. В. Сатаева ${ }^{\star * *}$ \\ * Институт истории, археологии и этнограбии им. А. Дониша АН Республики Тад- \\ жикистан, Душанбе, Таджикистан; ${ }^{*}$ Институт этнологии и антропологии РАН, \\ Москва, Россия; ${ }^{* *}$ Башкирский государственный аграрный университет, Уфа, Россия
}

DOI: $10.31600 / 978-5-907053-34-2-262-264$

Ключевые слова: Таджикистан, Бактрия, Тохаристан, подвижные скотоводы раннего средневековья, обряд захоронения, погребальный инвентарь, эквиды, палеоантропология, палеоэкология.

Могильник Шахидон, выявленный в 2011 г., занимает лессовый холм, возвышающийся

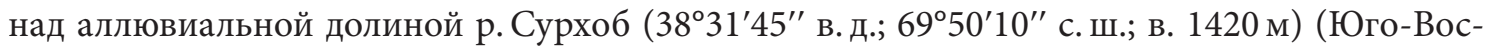
точный Таджикистан). В 2013-2015 гг. здесь было вскрыто 29 погребений, большая часть из которых разрушена или ограблена. Отмечается разнотипность погребальных сооружений: однокамерные катакомбные (10 могил), подбойные (13), ямные (2), двухкамерные катакомбно-ямные (2). В двух случаях тип могильной ямы определить не удалось. Не меньшим разнообразием отличаются положения скелетов: чаще всего погребенных укладывали на спину с согнутыми ногами, обращенными вверх коленями и со ступнями, упиравшимися в дно могильной ямы (10 случаев). В одном случае умерший был положен на спину в вытянутом положении, еще в одном - на спину, но его голени были уложены «снаружи и вдоль» бедер так, что пятки находятся под тазом. Имеются захоронения на левом боку в скорченном положении (3). За исключением одного двойного, все захоронения - одиночные. В 21 погребении вместе с останками человека присутствовали костные остатки животных. Они представлены скелетами или «шкурами» лошадей и гибридов осла и лошади, скелетами или «шкурами» крупного и мелкого рогатого скота (далее КРС и МРС); отдельными костями МРС. Под «шкурой» понимается захоронение шкуры животного, снятой вместе с головой и дистальными отделами конечностей. Кроме того, в погребениях встречены кости землеройных животных (сурок и дикобраз). Остатки эквид выявлены в 16 погребениях (в 11 - лошадь, в 5 - гибриды).

Погребальный инвентарь представлен наконечниками стрел и копий, мечом, ножами, стременами, бронзовыми зеркалами, бусами, серьгами, керамическими сосудами, монетами. Обычно в могилах присутствует поминальная пища - кости МРС и КРС. Микроскопическое изучение образцов грунта из заполнения ряда могил показало высокую 